\title{
Interactions Between Two Invertebrate Pathogens: An Endophytic Fungus and an Externally Applied Bacterium
}

\section{OPEN ACCESS}

Edited by: Chengshu Wang,

Center for Excellence in Molecular Plant Sciences, Chinese Academy of Sciences, China

Reviewed by:

Sheng-hua Ying,

Zhejiang University, China Bo Huang,

Anhui Agricultural University, China

${ }^{*}$ Correspondence:

Waqas Wakil

waqaswakee/@hotmail.com

David Shapiro-llan

david.shapiro@usda.gov

Specialty section:

This article was submitted to Fungi and Their Interactions, a section of the journal

Frontiers in Microbiology

Received: 22 December 2019 Accepted: 30 September 2020

Published: 30 November 2020

Citation:

Wakil W, Tahir M, Al-Sadi AM and

Shapiro-llan D (2020) Interactions Between Two Invertebrate Pathogens:

An Endophytic Fungus and an

Externally Applied Bacterium.

Front. Microbiol. 11:522368.

doi: 10.3389/fmicb.2020.522368

\author{
Waqas Wakil'1*, Muhammad Tahir 1,2, Abdullah M. Al-Sadi ${ }^{3}$ and David Shapiro-llan ${ }^{4 *}$ \\ 1 Department of Entomology, University of Agriculture, Faisalabad, Pakistan, ${ }^{2}$ Department of Entomology, College \\ of Agriculture and Environmental Sciences, The Islamia University, Bahawalpur, Pakistan, ${ }^{3}$ Department of Crop Sciences, \\ College of Agricultural and Marine Sciences, Sultan Qaboos University, Muscat, Oman, ${ }^{4}$ USDA-ARS, SEFTNRL, Byron, GA, \\ United States
}

The members of family Noctuidae exist in diverse environments and many species from this group are of agriculture importance, particularly Helicoverpa spp. Helicoverpa armigera (Hübner) (Lepidoptera: Noctuidae) is a major pest of many legumes and cereal crops. Due to environmental and regulatory concerns, safe alternatives to broad spectrum chemical insecticides are needed for the control of key noctuid pests such as $H$. armigera. A strain of Beauveria bassiana (Cordycipitaceae: Hypocreales) was evaluated for its ability to colonize endophytically in chickpea plants, and its effectiveness against second (L2) and fourth ( $\llcorner 4)$ larval instars of H. armigera. B. bassiana was inoculated to chickpea plants through injection and endophytic establishment was confirmed by re-isolating the fungi from leaf samples. A detached leaf assay was used to evaluate pathogenicity. Bacillus thuringiensis was also applied to both larval stages through leaf dip method. In a novel approach, combined treatments of bacteria and endophytic fungi were compared with single-pathogen treatments. Relative to the single treatments, the combined pathogen treatments exhibited an increase in larval mortality, and decrease in pupation, adult emergence and egg eclosion. Specifically, synergistic effects on mortality were observed when larvae were exposed to simultaneous application of $B$. bassiana $\left(1 \times 10^{8}\right.$ conidia $\left.\mathrm{ml}^{-1}\right)$ with $B$. thuringiensis $(0.75 \mu \mathrm{g}$ $\mathrm{ml}^{-1}$ ). Both instars exhibited varying level of growth, development, frass production, diet consumption and fecundity when exposed to the chickpea leaves inoculated with endophytic $B$. bassiana and dipped with sub-lethal doses of $B$. thuringiensis. These findings indicate that the integrated application of endophytic colonized $B$. bassiana and $B$. thuringiensis can be effectively used against $H$. armigera.

Keywords: endophytic colonization, Beauveria bassiana, Helicoverpa armigera, Bacillus thuringiensis, chickpea

\section{INTRODUCTION}

Among the leguminous crops chickpea (Cicer arietinum L.) is an important, nutritive and inexpensive crop among the people of the developing world (Sharma et al., 2007). Moreover chickpea plays a key role in increasing soil fertility through biological nitrogen fixation (Rao et al., 2008). From sowing to maturity a number of insect pests attack chickpea plants. Among these insect 
pests Helicoverpa armigera (Hübner) (Lepidoptera: Noctuidae) is the most serious (Chaudhary and Chaudhary, 1975; Khan, 1979; Chhabra, 1980). The insect feeds voraciously on tender parts and young pods of the plant and in severe cases can inflict losses up to $100 \%$ despite several rounds chemical insecticide applications (Tay et al., 2013). Global economic losses caused by this pest are more than $\$ 2$ billion annually. To combat this pest, insecticides continue to be the main strategy among the chickpea growers throughout the world. Overuse of chemical insecticides has led to significant resistance issues (Yang et al., 2013). Indeed, low susceptibility toward various chemicals has been reported by a number of scientists (e.g., Cameron et al., 1995; Ahmad et al., 1997; Gunning et al., 1998; Han et al., 1999; Martin et al., 2000). Thus, safe and effective alternative control measures must be sought.

Interest in the use of biopesticides is increasing due to the promising insecticidal properties of these materials and their safety to mammals, birds and other non-target organisms (Inglis et al., 2001). Among biocontrol agents, entomopathogenic fungi are promising measures for safe and long lasting control of voracious pests such as $H$. armigera. Encouraging results of several strains of Beauveria bassiana (Balsamo-Crivelli) Vuillemin (Cordycipitaceae: Hypocreales) against different larval stages of lepidopterous insect pests have been recorded (Nguyen et al., 2007). The use of fungi such as B. bassiana in different crop plants offers an alternative for the management of $H$. armigera (Sandhu et al., 1993).

An intriguing aspect of entomopathogenic fungi such as $B$. bassiana is that they can exist as endophytes in the plant (Vega et al., 2008). Endophytes are microorganisms that naturally reside within different plant parts (leaves stem and roots) without any apparent disease symptoms (i.e., lesions, retarded growth, and discoloration etc.) (Schulz and Boyle, 2005; Jalgaonwala et al., 2011). B. bassiana has been reported worldwide in its distribution, parasitizing various agriculturally important insect pests and has been recovered endophytically from many plants (Vega, 2008). To the benefit of the fungi, endophytically colonized $B$. bassiana receives lifelong protection against environmental factors such as UV light and rain. To the benefit of the plant, a key characteristic of this fungal family (as an endophyte) is the production of secondary metabolites (White et al., 2003), which provide protection against plant pathogens and arthropod pests. Endophytic relationships with entomopathogenic fungi such as $B$. bassiana can be generated by artificially inoculating flowers and or through foliar sprays, rhizome and root immersion, soil drenching, radical dressing and seed dressing (Parsa et al., 2013).

The efficacy of endophytic colonization by B. bassiana for control of various insect pests in different field crops has gained recent attention (Qayyum et al., 2015). The novel approach to introducing entomopathogenic fungi into a system demonstrates a variety of symbiotic relationships with host plants, and exploits these interactions to open new perspectives regarding pest management and improving plant health. Numerous studies have confirmed the protection by endophytic fungi against plant diseases, insects (Arnold et al., 2003; O'Hanlon et al., 2012) or plant parasitic nematodes (Waweru et al., 2014). A number of success stories of endophytic relationships in banana (Akello et al., 2008), date palm (Gómez-Vidal et al., 2006), cacao (Posada and Vega, 2005), coffee (Posada et al., 2007), jute (Biswas et al., 2012), maize (Cherry et al., 2004), pecan (Ramakuwela et al., 2019), potato (Jones, 1994), sorghum (Tefera and Vidal, 2009), tomato (Leckie, 2002; Qayyum et al., 2015) and Theobroma gileri, a close relative of cocoa (Evans et al., 2003) has confirmed broad utility of the approach in controlling insect pests of many important crops. The symbiotic relation of the fungal entomopathogen B. bassiana has become an integral part of Conopomorpha cramerella (Snellen) (Lepidoptera: Gracillariidae) management in Indonesia, Malaysia and Philippines (Posada and Vega, 2005). The introduction of B. bassiana as fungal endophyte in maize had success in providing control of Ostrinia nubilalis (Hübner) (Arnold and Lewis, 2005). Endophytic B. bassiana has been shown to induce infection and protect against $H$. armigera in prior studies though not in a chickpea system (Qayyum et al., 2015).

Another promising group of biological control agents for noctuid pests such as $H$. armigera are entomopathogenic bacteria from the genus Bacillus. These bacteria are key antagonists of numerous insect pests of economic importance in various cropping systems (Salama et al., 2004). Bacillus thuringiensis is often an integral part of products used in biological control strategies worldwide; about $90 \%$ microbial pesticides used globally are B. thuringiensis with annual sales of about $\$ 3$ billion (although that is only 5\% of total crop protection market) (Marrone, 2014; Kumar and Singh, 2015; Olson, 2015; Damalas and Koutroubas, 2018). Numerous species of this genus particularly $B$. thuringiensis Berliner (Bt) are frequently used against a vast array of insect pests from the orders Coleoptera, Lepidoptera and Diptera etc; these bacteria exhibit a high degree of specificity toward the host and specific stage of the host (Salama et al., 2004).

Combined application of more than one biocontrol agent can result in synergistic levels of pest control. For example, Wraight and Ramos (2005) observed that integrated application of $B$. bassiana and $B$. thuringiensis resulted in synergistic interactions against some insect species. Later, in another study, synergistic interactions between $B$. bassiana and $B$. thuringiensis were confirmed against Colorado potato beetle (Leptinotarsa decemlineata Say), which was consistent under varying environmental regimes (Wraight and Ramos, 2017). Similar results were reported from the combined application of both agents against Mediterranean flour moth larvae (Sandner and Cichy, 1967). However, there is a dearth of information on using $B$. thuringiensis in combination with entomopathogenic fungi in their endophytic state. The present study targeted $H$. armigera infestation in chickpea managed through endophytic colonization of $B$. bassiana alone and in combination with B. thuringiensis, impact of treatments on the development, diet consumption, frass production and weight gain was also assessed. 


\section{MATERIALS AND METHODS}

\section{Helicoverpa armigera Collection and Rearing}

Larvae of $H$. armigera for the experiments were obtained from the culture collection of the Microbial Control Laboratory, Department of Entomology, University of Agriculture, Faisalabad, Pakistan. The culture was maintained in the laboratory for more than 30 generations on an artificial diet (Wakil et al., 2011). The diet consists of chickpea flour (125 g), red kidney beans (125 g), canned tomato paste ( $25 \mathrm{~g})$, yeast ( $40 \mathrm{~g})$, agar $(17 \mathrm{~g})$, and a vitamin mixture $(10 \mathrm{ml})$ mixed thoroughly in distilled water $(1300 \mathrm{ml})$. Due to their cannibalistic nature larvae were reared individually in plastic vials $(7 \mathrm{~cm}$ height, $3 \mathrm{~cm}$ in diameter). After pupation, they were transferred to small plastic boxes for adult emergence. The adult's diet contained $10 \%$ honey solution. The rearing conditions were maintained at $25^{\circ} \mathrm{C}$ and $65 \% \mathrm{RH}$ in an incubator (MIR-254, Sanyo, Japan).

\section{Isolation of Endophytic Fungi}

For isolation of endophytic fungi, chickpea fields were visited in different chickpea growing areas of Punjab, Pakistan. The plants were selected on the basis of cadavers lying under the plants indicating the potential presence of endophytic fungi. Endophytically colonized fungi were isolated following the method of Arnold et al. (2000). Before isolation, plants were carefully uprooted, sealed in a zipper bag, transferred to the laboratory and stored at $4^{\circ} \mathrm{C}$ until processing. For isolation, leaves were first washed with running tap water and dried for $10 \mathrm{~min}$. A small piece $\left(3 \mathrm{~mm}^{2}\right)$ was cut from the center of the leaf with sterilized scissors followed by surface sterilization with $70 \%$ ethanol for $2 \mathrm{~min}$ followed by $2 \%$ sodium hypochlorite for $3 \mathrm{~min}$ and then 3 rinses in distilled water. Leaf pieces were dried on sterilized tissue paper and placed on Petri dishes containing $20 \mathrm{ml}$ of Potato Dextrose Agar (PDA) (Merck, Germany) amended with chloramphenicol $\left(50 \mu \mathrm{g} \mathrm{ml}^{-1}\right)$, streptomycin sulfate $(50 \mu \mathrm{g}$ $\mathrm{ml}^{-1}$ ) (Sigma, St Louis, MO, United States) and $0.5 \mathrm{~g} \mathrm{~L}^{-1}$ of dodine (65\%). After 14 days on the media plates, leaf pieces that exhibited fungal growth were transferred to glass tubes on Sabouraud Dextrose Agar (SDA) (BD, France) media slants for storage and future use. The fungus was identified (Barnett and Hunter, 1999) as B. bassiana on morphological characteristics: conidia were produced in clusters with a characteristic snowball shape and the conidiogenous cells had a flask shaped basal section with a zig zag rachis.

\section{Conidial Suspension}

Beauveria bassiana isolate was mass cultured in PDA medium enriched with $1 \%$ yeast extract (Watson et al., 1995) containing $50 \mu \mathrm{g} \mathrm{ml}^{-1}$ of chloramphenicol. The plates were incubated at room temperature and humidity level $\left(25^{\circ} \mathrm{C}\right.$ and $\left.65 \% \mathrm{RH}\right)$, $14 \mathrm{~h}$ Light: $10 \mathrm{~h}$ Dark photoperiod. Conidia from each plate were harvested by scraping with a sterilized scalpel, and conidial powder was dried and stored at $4^{\circ} \mathrm{C}$ until formulation and use. For experimentation, conidial powder was suspended in sterile distilled water containing 0.01\% (v/v) Tween-80 (Merck,
Germany). The conidia were dislodged into the suspension with a glass rod. The suspension was filtered through a double layer of sterile cheesecloth (mesh: 36 by 36 threads $\mathrm{cm}^{-2}$ ) to remove clumps of mycelia. The conidial suspension was poured into a sterile glass tube and vortexed for spore viability determination (Lezama-Gutiérrez et al., 2001). Spore concentration was determined with a hemocytometer and serial conidial dilutions were made until required conidial concentrations were achieved. The germination rate of $B$. bassiana conidia was $>93 \%$ determined prior to each bioassay.

\section{Colonization of Endophytic Fungi in Chickpea Plants}

The $B$. bassiana isolate was inoculated in chickpea seedlings via injection of a conidial suspension into the plant. The chickpeas were grown in a glass house at the University of Agriculture, Faisalabad. Two spore concentrations $\left(1 \times 10^{5}\right.$ and $1 \times 10^{8}$ conidia $\mathrm{ml}^{-1}$ ) for colonization were prepared in $0.01 \%$ Tween80. Fifteen plants were selected for each replication and three replications were used for each treatment. Forty-day old chickpea plants were selected for injection; injections were made to the stem base with $1 \mathrm{ml}$ of respective doses of fungal suspension using a sterile syringe. Control plants were injected with $1 \mathrm{ml}$ of sterile water containing $0.01 \%$ Tween-80. The entire experiment was repeated three times.

\section{Preparation of $B$. thuringiensis Spore-crystal Mixtures}

The strain of $B$. thuringiensis isolate was obtained from the Microbial Control Laboratory collection (Department of Entomology, University of Agriculture, Faisalabad) and was originally obtained from National Center for Genetic Engineering and Biotechnology (BIOTEC) in Thailand. This strain was then subjected to sporulation by culturing in $50 \mathrm{ml}$ nutrient broth media. Harvesting of cultures was carried out by centrifugation at $6000 \mathrm{rpm}$ for $15 \mathrm{~min}$ (Crecchio and Stotzky, 2001; Hernández et al., 2005). The pellets received three washings with cold $1 \mathrm{M} \mathrm{NaCl}$ and re-suspended. Spore concentration was adjusted by 1:100 dilutions and optical density was measured at $600 \mathrm{~nm}$ (Hernández et al., 2005), then the samples were stored in refrigerator until used (Wakil et al., 2013).

\section{Mortality Assays}

Bioassays were conducted to assess the endophytic efficacy of B. bassiana against second (L2) and fourth (L4) instar larvae of $H$. armigera. Fifteen leaves from inoculated (three weeks earlier) and un-inoculated (control) plants were detached and offered to L2 and L4 instar $H$. armigera larvae. For $B$. thuringiensis treatments, three concentrations $\left(0.50,0.75\right.$, and $\left.1.0 \mu \mathrm{g} \mathrm{ml}^{-1}\right)$ were prepared. A piece of chickpea leaf $\left(2 \times 2 \mathrm{~cm}^{2}\right)$ was immersed in respective doses of $B$. thuringiensis suspension for 60 s and offered to the respective larval stages individually. The larvae were allowed to feed on treated leaves for $48 \mathrm{~h}$ and shifted to the artificial diet for rest of the period. In combined treatments $B$. bassiana inoculated leaves were immersed in respective doses of $B$. thuringiensis 
suspension for $60 \mathrm{~s}$ and then offered to the larvae. Mortality was recorded after every $48 \mathrm{~h}$ up to pupation for both larval instars. The larvae were prodded with a blunt needle and those unable to move in a coordinated manner were considered as dead (Ma et al., 2008). From the surviving individuals, percentage pupation, adult emergence and egg eclosion were also recorded. Three replicates of fifteen larvae were used for each treatment and same count of larvae fed on normal leaves served as the non-treated check. All the treatments were incubated at $25^{\circ} \mathrm{C}$ and $65 \% \mathrm{RH}$ and $14 \mathrm{~h}$ Light: $10 \mathrm{~h}$ Dark photoperiod in an incubator (Sanyo, Japan). The entire experiment was repeated three times.

\section{Effect of Sub-lethal Doses on Development of $\boldsymbol{H}$. armigera}

To determine the effect of sub-lethal doses of endophytic B. bassiana $\left(1 \times 10^{5}\right.$ conidia $\left.\mathrm{ml}^{-1}\right)$ and $B$. thuringiensis $(0.20$, 0.30 , and $0.40 \mu \mathrm{g} \mathrm{ml}^{-1}$ ) on developmental parameters viz. larval duration, larval weight, pre-pupal duration, pre-pupal weight, adult longevity (male and female) and adult weight (male and female) was recorded on L4 instar larvae of $H$. armigera. The sublethal doses were selected based on preliminary assays. A piece of endophytically colonized $B$. bassiana and $B$. thuringiensis were applied alone and in combination against L4 instar larvae and incubated at above mentioned conditions. The larvae were allowed to feed on treated leaves for $48 \mathrm{~h}$ and then shifted to the artificial diet for rest of the period. After pupation, the pupae were transferred to separate small plastic jars for adult emergence. The adults were fed on $10 \%$ honey solution. Adults were observed on daily basis and mortality was determined until the death of last adult. Each treatment consisted of 45 larvae with three replicates and the experiment was repeated thrice. The environmental conditions were set at $25^{\circ} \mathrm{C}$ and 65\% $\mathrm{RH}$ and $14 \mathrm{~h}$ Light: $10 \mathrm{~h}$ Dark photoperiod inside the incubator.

\section{Effect of Sub-lethal Doses on Diet Consumption, Weight Grain and Frass Production}

A new batch of 6 th instar $H$. armigera (L6) were offered sublethal doses of endophytic $B$. bassiana $\left(1 \times 10^{5} \mathrm{ml}^{-1}\right)$ and $B$. thuringiensis $\left(0.20 \mu \mathrm{g} \mathrm{ml}^{-1}\right)$. A piece of endophytically colonized chickpea leaf alone and in combination with $B$. thuringiensis was offered to the larvae. The larvae were allowed to feed on treated leaves for $48 \mathrm{~h}$ and then shifted to the artificial diet for rest of the period. Before exposing to the leaves each larva was weighed and transferred to a rearing vial. Every day until the larvae pupated or died, larvae were moved to new vials individually and provided with fresh diet every day. Frass produced during this period was separated from vials using the tip of a fine camel hair brush; the frass was then weighed. Diet left unused in each vial was recovered and dried in a drying oven at $80^{\circ} \mathrm{C}$. Prior to the assay, diet in 30 cups was dried to obtain an estimate of the original dry weight. Diet consumption of each larva was determined by subtracting the weight after feeding from before. Moreover, total frass production and weight gain during this period were also determined.

\section{Statistical Analysis}

Percentage mortality was recorded and corrected for control mortality using Abbott (1925) formula. The data were then subjected to a one-way analysis of variance in Minitab statistical package (Minitab 2003) using Tukey's Kramer test (HSD) (Sokal and Rohlf, 1995) at 5\% significance level. The type of interaction between combined treatments of $B$. thuringiensis and B. bassiana was determined by CTF analysis; $\mathrm{CTF}=(\mathrm{Oc}-\mathrm{Oe}) / \mathrm{Oe} \times 100$, where CTF is the co-toxicity factor, Oc is the observed mortality (\%) in combined application, and Oe the expected mortality (\%), that is the sum of individual mortality (\%) encountered in each of the treatments used in the combination (Mansour et al., 1966). The interactions were categorized as additive, synergistic or antagonistic: $\mathrm{CTF} \geq 20$ indicates synergism, $\mathrm{CTF}>-20$ indicates additivity, and CTF $<-20$ indicates antagonism (Mansour et al., 1966; Wakil et al., 2012).

\section{RESULTS}

\section{Mortality Assays}

Treatment effects were detected in the mortality assays. Table $\mathbf{1}$ presents the statistical results from the factorial analysis including treatment and interaction effects. Table 2 presents mean mortalities and the multiple range distribution (HSD test). Significant differences were recorded for mortality among different treatments and instars (treatment: $F_{7}, 160=199.67$, $P \leq 0.05$; instar: $\left.F_{1}, 161=64.21, P \leq 0.05\right)$ but a nonsignificant interaction was recorded for instar $\times$ treatment $\left(F_{7}, 161=1.54, P=0.09\right)$ (Table 1). A synergistic effect $(\mathrm{CTF} \geq 20)$ on mortality was observed when larvae were exposed to simultaneous application of endophytic $B$. bassiana and $0.75 \mu \mathrm{g} \mathrm{ml}^{-1}$ of $B$. thuringiensis in case of both instars tested (Table 2).

There were higher numbers of dead larvae observed when L2 instar exposed to the treatments than L4 instar larvae (Table 2). The combined application of endophytic B. bassiana and $B$. thuringiensis proved more fatal to both instars compared to single application of each agent. For instance, the highest mortality $(77.40 \%)$ for L2 instar larvae was observed where simultaneous application of $B$. bassiana and $B$. thuringiensis (0.75 $\mathrm{mg} \mathrm{ml}^{-1}$ ) was applied followed by $68.38 \%$ when treated with B. bassiana and B. thuringiensis $\left(1.0 \mu \mathrm{g} \mathrm{ml}^{-1}\right)$ and $49.07 \%$ when treated with $B$. bassiana $\left(1 \times 10^{8}\right.$ conidia $\left.\mathrm{ml}^{-1}\right)$ and B. thuringiensis $\left(0.50 \mu \mathrm{g} \mathrm{ml} \mathrm{m}^{-1}\right)$ (Table 2). Additive effects $(\mathrm{CTF} \leq 20)$ were recorded when the tested instars were treated with low doses of $B$. thuringiensis in integration with endophytic $B$. bassiana while an antagonistic effect was observed at highest dose of $B$. thuringiensis and endophytic $B$. bassiana (Table 2). A similar trend in mortality was recorded for both 2 nd and 4 th instars.

Percentage pupation, adult emergence and egg eclosion from surviving individuals generally decreased within single and combined treatments as the dose rate of $B$. thuringiensis increased 
TABLE 1 | Factorial analysis of mortality, pupation, adult emergence and egg eclosion of $H$. armigera treated with endophytically colonized $B$. bassiana and B. thuringiensis.

\begin{tabular}{|c|c|c|c|c|c|c|c|c|c|}
\hline \multirow[t]{2}{*}{ Source } & \multirow[t]{2}{*}{$d f$} & \multicolumn{2}{|c|}{ Mortality } & \multicolumn{2}{|c|}{ Pupation } & \multicolumn{2}{|c|}{ Adult emergence } & \multicolumn{2}{|c|}{ Egg eclosion } \\
\hline & & $\boldsymbol{F}$ & $P$ & $\boldsymbol{F}$ & $P$ & $\boldsymbol{F}$ & $P$ & $\boldsymbol{F}$ & $P$ \\
\hline Instar & 1 & 64.21 & $\leq 0.05$ & 61.37 & $\leq 0.05$ & 54.23 & $\leq 0.05$ & 36.21 & $\leq 0.05$ \\
\hline Treatment & 7 & 199.67 & $\leq 0.05$ & 222.34 & $\leq 0.05$ & 213.29 & $\leq 0.05$ & 249.0 & $\leq 0.05$ \\
\hline Instar $\times$ treatment & 7 & 1.54 & 0.09 & 0.58 & 0.53 & 0.59 & 0.67 & 0.67 & 0.38 \\
\hline Error & 145 & - & - & - & - & - & - & - & - \\
\hline Total & 160 & - & - & - & - & - & - & - & - \\
\hline
\end{tabular}

TABLE 2 | Mortality (mean \pm SE)\% of L2 and L4 instar H. armigera treated with endophytic B. bassiana (Bb: $1 \times 10^{8}$ conidia ml ${ }^{-1}$ ) alone and in combination with B. thuringiensis (Bt1: 0.50; Bt2: 0.75; Bt3: $1.0 \mu \mathrm{g} \mathrm{ml}^{-1}$ ).

\begin{tabular}{|c|c|c|c|c|c|c|c|c|}
\hline \multirow[t]{2}{*}{ Treatments } & \multicolumn{4}{|c|}{ Second instar } & \multicolumn{4}{|c|}{ Fourth instar } \\
\hline & Observed mortality (\%) & $\begin{array}{l}\text { Expected } \\
\text { mortality }\end{array}$ & CTF & Type of interaction & Observed mortality (\%) & $\begin{array}{l}\text { Expected } \\
\text { mortality }\end{array}$ & CTF & Type of interaction \\
\hline $\mathrm{Bb}$ & $27.13 \pm 1.36 d$ & & & & $19.69 \pm 1.19 \mathrm{e}$ & & & \\
\hline Bt1 & $19.96 \pm 1.11 d$ & & & & $14.87 \pm 1.07 e$ & & & \\
\hline $\mathrm{Bt2}$ & $33.64 \pm 2.02 d$ & & & & $25.74 \pm 1.25 \mathrm{de}$ & & & \\
\hline $\mathrm{Bt3}$ & $58.05 \pm 2.80 \mathrm{bc}$ & & & & $49.36 \pm 2.34 b c$ & & & \\
\hline $\mathrm{Bb}+\mathrm{Bt} 1$ & $49.07 \pm 2.13 c$ & 47.09 & 4.03 & Additive & $35.92 \pm 1.70 \mathrm{~cd}$ & 34.56 & 3.78 & Additive \\
\hline $\mathrm{Bb}+\mathrm{Bt} 2$ & $77.40 \pm 3.10 \mathrm{a}$ & 60.77 & 21.48 & Synergistic & $58.82 \pm 2.77 a$ & 45.43 & 22.76 & Synergistic \\
\hline $\mathrm{Bb}+\mathrm{Bt3}$ & $68.38 \pm 3.03 \mathrm{ab}$ & 85.18 & -24.5 & Antagonistic & $53.45 \pm 2.31 \mathrm{ab}$ & 65.05 & -21.70 & Antagonistic \\
\hline$d f$ & 6 & & - & - & 6 & & - & - \\
\hline$F$ & 40.6 & & - & - & 31.6 & & - & - \\
\hline$P$ & $\leq 0.05$ & & - & - & $\leq 0.05$ & & - & - \\
\hline
\end{tabular}

Means followed by the same letters within each column are not significantly different; HSD test $P \leq 0.05$.

(Figure 1). Overall, pupation, adult emergence and egg eclosion was lower in the combination treatments than the single-applied treatments (Figure 1).

\section{Effect of Sub-lethal Doses on Development of $\boldsymbol{H}$. armigera}

When larvae were encountered different sub-lethal concentrations of $B$. thuringiensis and B. bassiana $\left(1 \times 10^{5}\right.$ conidia $\mathrm{ml}^{-1}$ ) and endophytically colonized chickpea leaves, significant variation was recorded for all factors including incubation of egg period: $F_{7}, 71=45.4, P \leq 0.05$; larval duration: $F_{7}, 71=17.3, P \leq 0.05$; pre-pupal duration: $F_{7}, 71=30.70$, $P \leq 0.05$; pupal duration: $F_{7}, 71=21.90, P \leq 0.05$; total immature period: $F_{7}, 71=63.1, P \leq 0.05$; pre-oviposition period: $F_{7}, 71=10.8, P \leq 0.05$; oviposition period: $F_{7}, 71=36.4, P \leq 0.05$; post-oviposition period: $F_{7}, 71=16.0, P \leq 0.05$; daily fecundity: $F_{7}, 71=214.0, P \leq 0.05$; total fecundity $1: F_{7}, 71=1902.0$, $P \leq 0.05$; adult longevity: (female: $F_{7}, 71=30.3, P \leq 0.05$ and male: $F_{7}, 71=35.0, P \leq 0.05$ ). Overall, incubation of eggs, larval, pre-pupal period, pupal duration, total immature period and preoviposition period increased as the dose rate of $B$. thuringiensis application increased, and these parameters tended to be shorter for the combine treatments than the individual treatments (Table 3). In contrast, oviposition, post-oviposition period, fecundity daily, fecundity total and adult longevity (male and female) decreased as the dose rate of $B$. thuringiensis application increased. Here again the combined treatments were more effective than single treatments (Table 3).

\section{Effect of Sub-lethal Doses on Diet Consumption, Weight Grain and Frass Production}

Diet consumption by 6 th instar larvae was significantly influenced by the treatments (Bt: $F_{9}, 89=169.0, P \leq 0.05$; Bb: $F_{10}, 98=56.5, P \leq 0.05 ; \mathrm{Bt}+\mathrm{Bb}: F_{12},{ }_{116}=46.8, P \leq 0.05$; Control: $\left.F_{6}, 62=167.0, P \leq 0.05\right)$; diet consumption was lower in combined treatments compared with sole applications. Diet consumption was the lowest for the endophytic B. bassiana and $B$. thuringiensis while the highest consumption was recorded in the control treatment (Figure 2). Frass production was also significantly influenced by treatments applied (Bt: $F_{9}, 89=39.4$, $P \leq 0.05$; Bb: $F_{10}, 98=44.5, P \leq 0.05 ; \mathrm{Bt}+\mathrm{Bb}: F_{12}, 116=44.7$, $P \leq 0.05$; Control: $\left.F_{6}, 62=178.0, P \leq 0.05\right)$. More frass production was recorded during the initial days of treatments and gradually decreased to zero before pupation. On the other hand, the highest level of frass production was found in non-treated larvae (Figure 3). Larvae treated with sub-lethal single-treatment concentrations of $B$. bassiana and $B$. thuringiensis gained more weight compared to their combined application (Figure 4). Weight gain was also significantly different among the treatments (Bt: $F_{9}, 89=734.0, P \leq 0.05 ; \mathrm{Bb}: F_{10}, 98=529.0, P \leq 0.05 ; \mathrm{Bt}+\mathrm{Bb}$ : $F_{12}, 116=166.0, P \leq 0.05$; Control: $\left.F_{6}, 62=175.0, P \leq 0.05\right)$. 

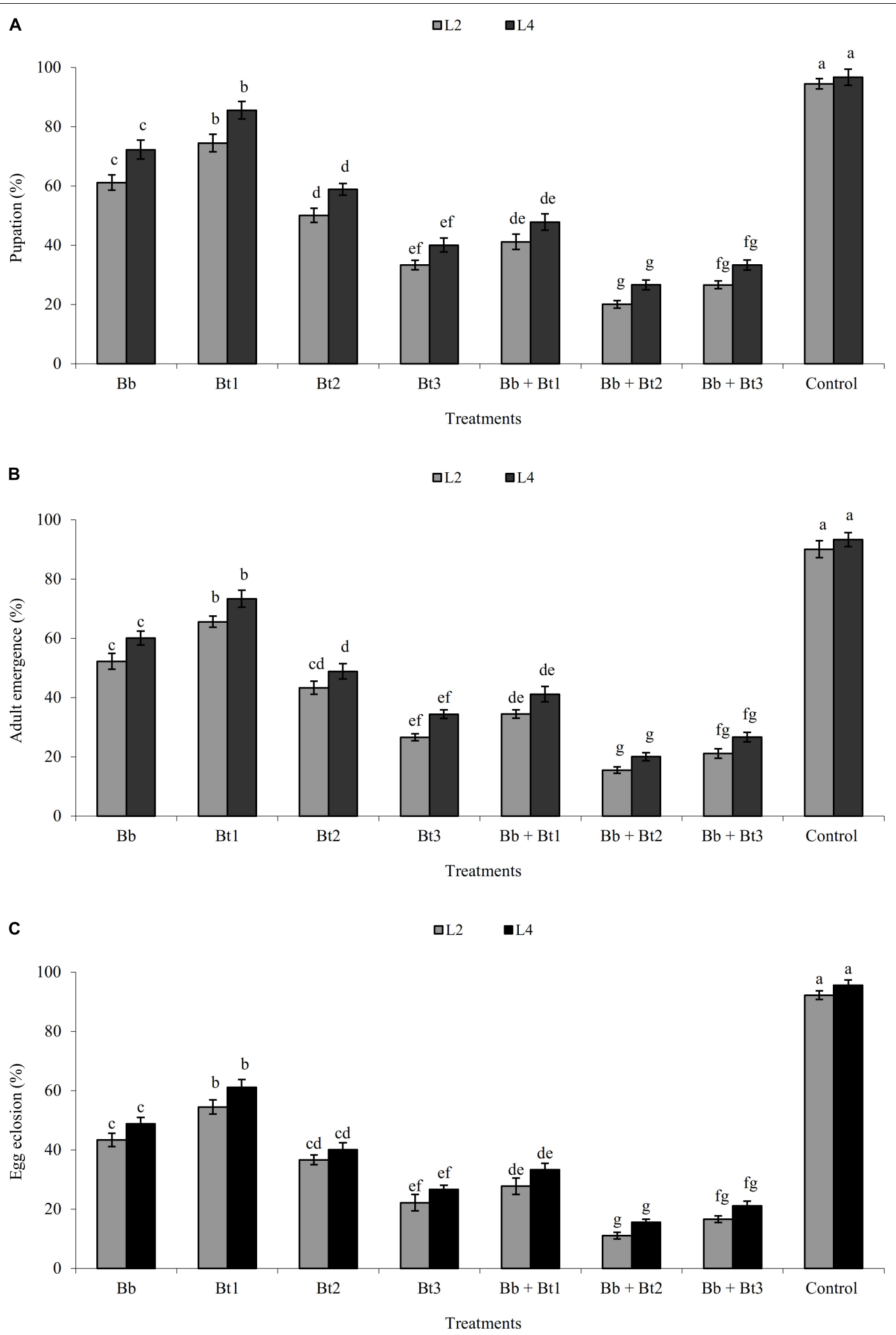

FIGURE 1 | Pupation (A), adult emergence (B), and egg eclosion (C) of L2 and L4 instars (mean \pm SE)\% of $H$. armigera treated with endophytic B. bassiana

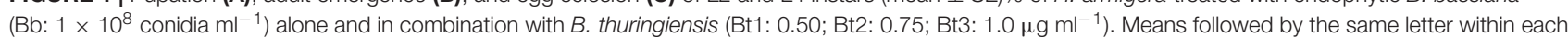
larval instar are not significantly different; HSD test $P \leq 0.05$. 


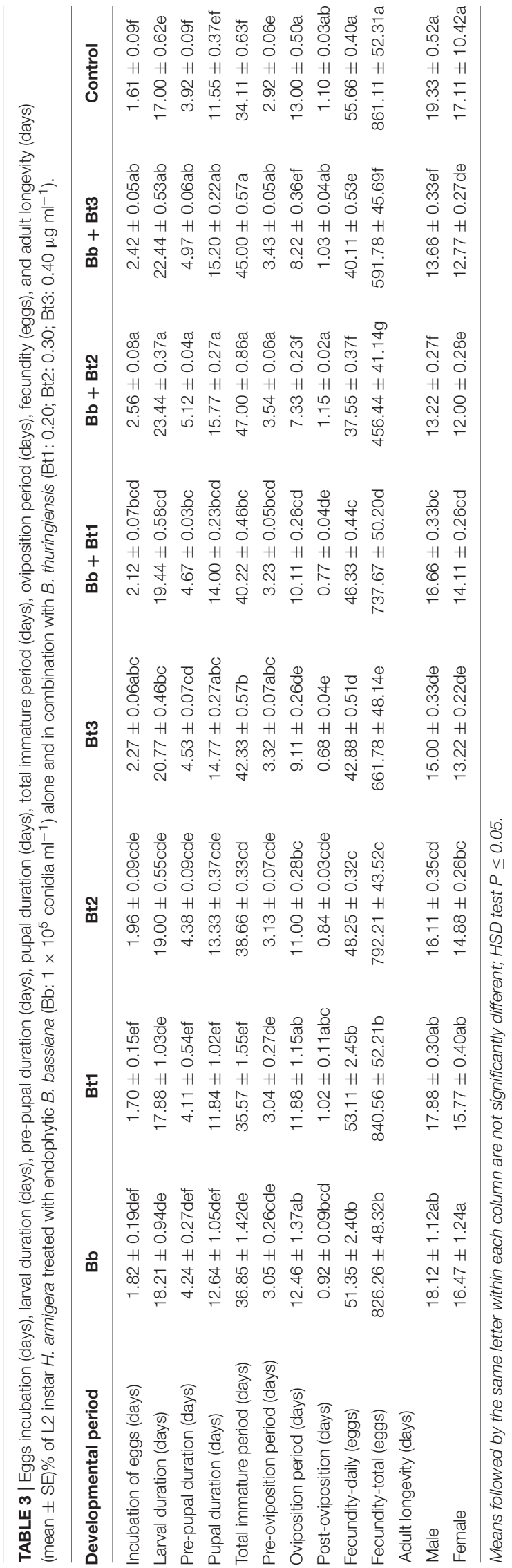

\section{DISCUSSION}

Our study indicated that B. bassiana successfully colonized chickpea plants endophytically and caused considerable mortality in $H$. armigera larvae. Similarly, successful colonization of B. bassiana in corn plant tissue resulted in high mortality in larvae of $O$. nublialis when encountering endophytically colonized plants (Bing and Lewis, 1991, 1992a,b). In banana plants endophytically colonized B. bassiana caused high larval mortality in banana root borer; eggs and adults that emerged from infected larvae showed mycosis (Akello et al., 2008). In another example, mycosed larvae of $H$. zea were also reported from tomato plants inoculated with B. bassiana (Powell et al., 2009). The authors (Powell et al., 2009) also observed fungal infection within $H$. armigera larvae and later confirmed this by visual fungal growth on cadavers after feeding on tomato (Powell et al., 2007). The injection of B. bassiana and subsequent pathogenic endophyte status against the target pest, $H$. armigera, has been successfully demonstrated previously (Qayyum et al., 2015). In the current study we are not necessarily advocating injection as a practical means where a farmer would go out and infect every single plant in his or her field. Rather, we are putting forth this study as a model system indicating the unique synergistic interaction between $B$. thuringiensis and B. bassiana when it is in the plant as an endophyte.

Endophytic entomopathogenic fungi mostly belong to order Hypocreales of division Ascomycota (Roy et al., 2006). They are classified as Class II endophytes due to the ability to endophytically colonize both above and below the ground tissue of the host plant (Rodriguez et al., 2009; QuesadaMoraga et al., 2014). Entry into the plant stems from the germ tube formed from conidia, from which fungal hyphae produce and penetrate into the plant tissues through the stomata or with the aid of fungal enzymes and turgor pressure produced from the hyphae via the epidermal cells (Wagner and Lewis, 2000). The main objective of our study was to evaluate the effectiveness of $B$. bassiana endophytically colonized into chickpea plants against $H$. armigera and therefore we did not investigate the factors influencing fungal penetration and its colonization inside the plants. However, literature reveals that researchers have investigated different plant/leaf factors affecting the colonization of endophytic fungi. Endophytic fungi have been reported in every plant species examined to date (Tejesvi et al., 2007) and colonize vegetative and reproductive parts of their host plants (Arnold et al., 2003). Cannon and Simmons (2002) observed that endophytic colonization of species of Colletotrichum, Nodulisporium, Pestalotiopsis, and Phomopsis was greater in the midrib than in laminar tissue, and slightly greater at the tip of the lamina compared with the base of the leaves. Some other studies have been conducted to evaluate the richness and the distribution of endophytes in the plant leaves and found that some taxa were leaf age specific and composition of endophytes varied with leaf region (Hilarino et al., 2011). Other studies indicate that old leaves support more endophytes than younger leaves (Suryanarayanan and Thennarasan, 2004). Fernandes et al. (2011) reported that changes in leaf biochemistry influenced endophytic colonization 


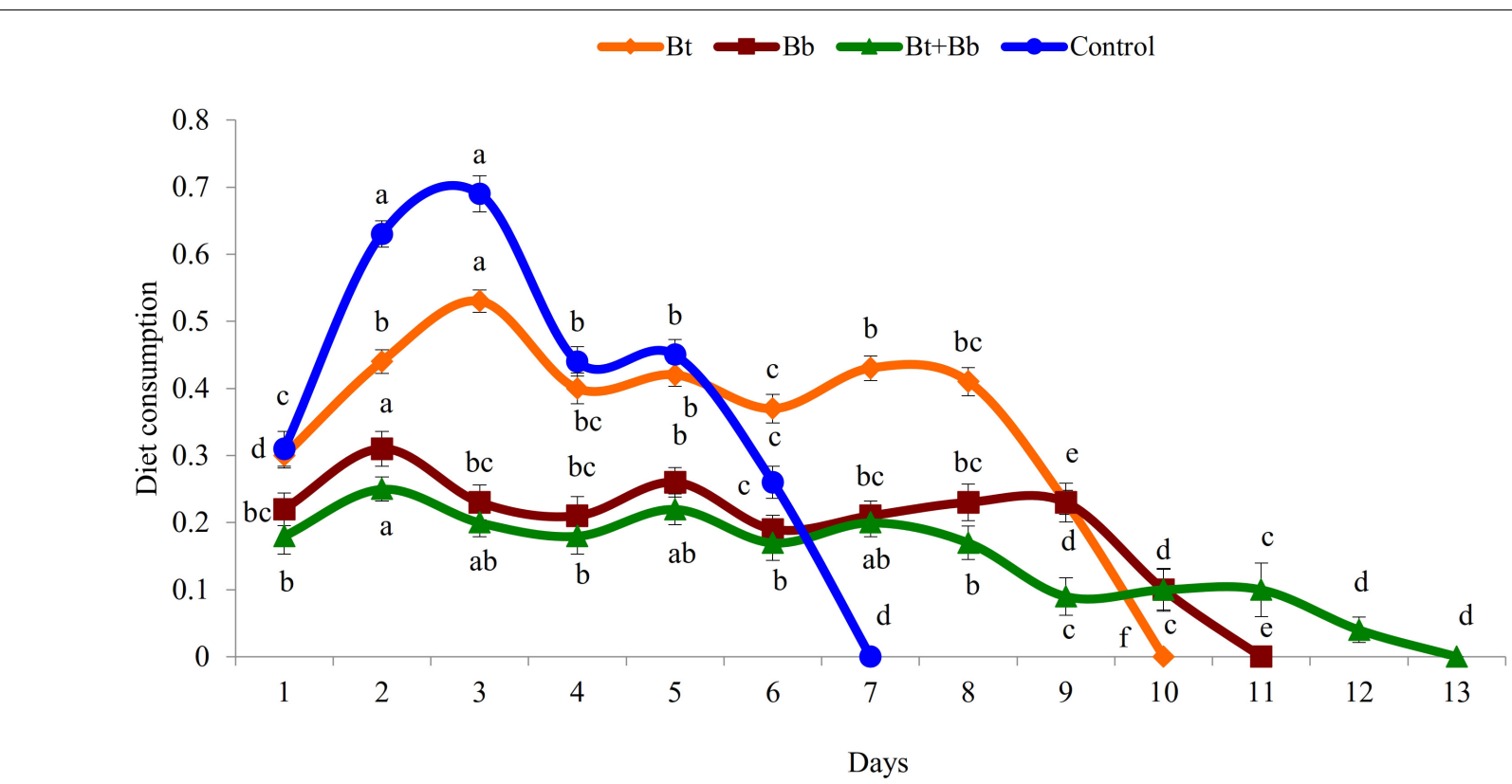

FIGURE 2 | Diet consumption (g) in last instar H. armigera treated with endophytic $B$. bassiana $\left(\mathrm{Bb}: 1 \times 10^{5} \mathrm{conidia} \mathrm{ml}^{-1}\right.$ ) alone and in combination with B. thuringiensis (Bt1: $0.20 \mathrm{\mu g} \mathrm{ml}^{-1}$ ). Means followed by the same letter within each treatment are not significantly different; HSD test $P \leq 0.05$.

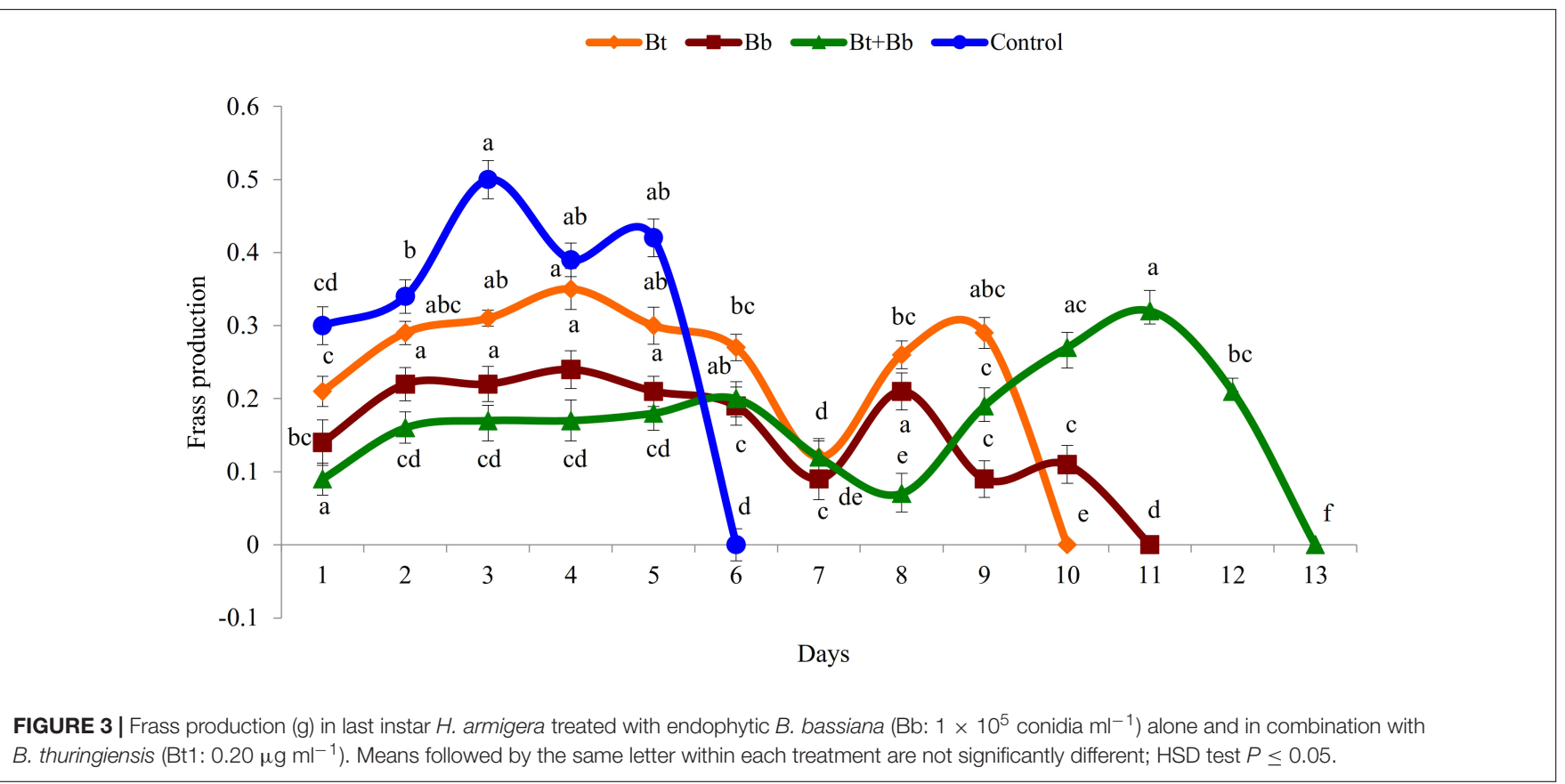

with consequences for endophyte distribution. On the other hand, Arnold and Herre (2003) argued that leaf chemistry has a minor role in endophyte colonization. The relation of a polyphenolic biomolecule "tannin" with endophytic fungal colonization in the leaves of Bauhinia brevipes (Fabaceae) has also been studied (Cornelissen and Fernandes, 2001). It would indeed be interesting to know what other fungi colonize the plant along with $B$. bassiana, which is an interesting point for further study.
The mode of action of endophytic entomopathogenic fungi is still unclear but most of the researchers believe that the endophytic entomopathogenic fungi do not cause direct infection rather mortality results from feeding deterrence or antibiosis through inducing systemic plant defenses. There are many studies involving the artificial colonization of endophytic fungi in different plants and subsequent mortality of target insect species. For example, two strains of $B$. bassiana were 


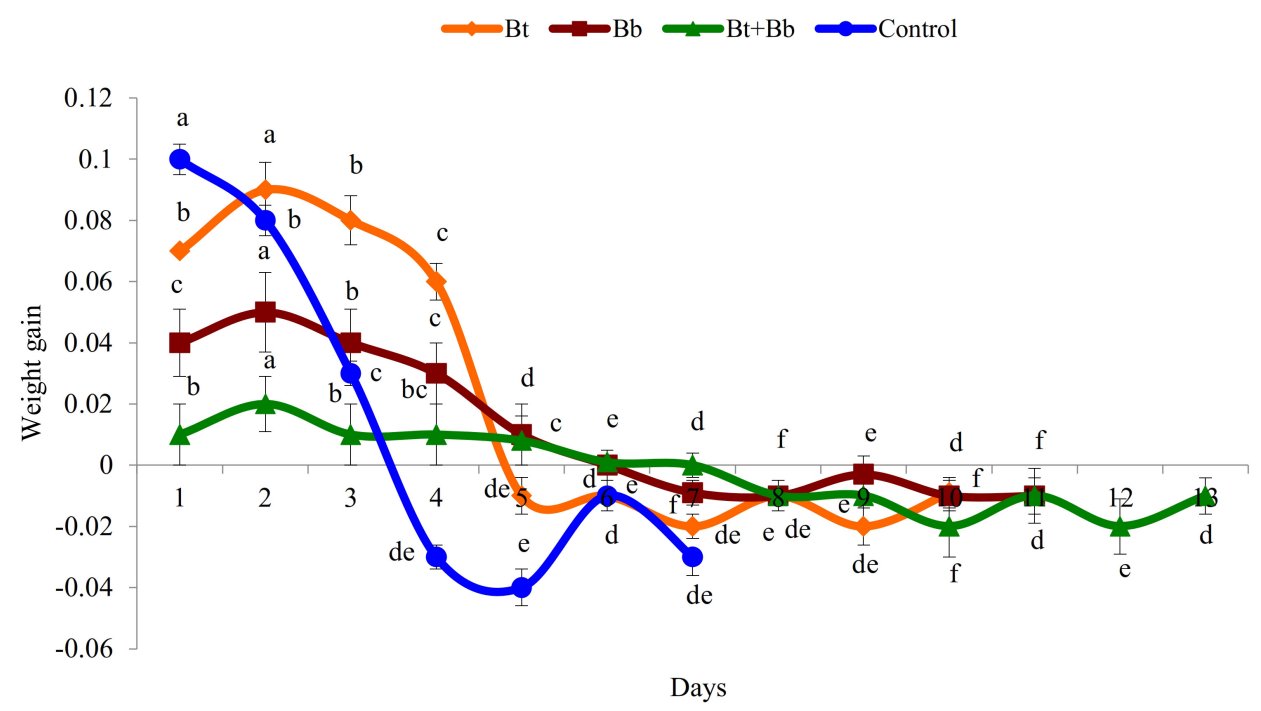

FIGURE 4 | Weight gain $(\mathrm{g})$ in last instar $\mathrm{H}$. armigera treated with endophytic $B$. bassiana $\left(\mathrm{Bb}: 1 \times 10^{5} \mathrm{conidia}^{\mathrm{ml}} \mathrm{I}^{-1}\right)$ alone and in combination with $B$. thuringiensis (Bt1: $0.20 \mu \mathrm{g} \mathrm{ml}^{-1}$ ). Means followed by the same letter within each treatment are not significantly different; HSD test $P \leq 0.05$.

successfully established as endophytes in Citrus limon (L.) Osbeck plants as indicated through systemic colonization of the various citrus plant parts i.e., leaves, stems and roots by BB Fafu-13 strain. Endophytic B. bassiana induced $10 \%$ to $15 \%$ mortality within 7 days of exposure when adult psyllids that were allowed to feed on the leaves of treated plants, and there was no mycosis detected on any of the dead psyllids (Bamisile et al., 2019). In another study, very low levels of mycosis (5.4-9.2\%) was detected from cadavers of horse-chestnut leaf miner Cameraria ohridella Deschka \& Dimić from two different strains of $B$. bassiana AM-EF0111 and AM-EP0715 (Barta, 2018). Jaber et al. (2018) reported no fungal outgrowth in sweetpotato whitefly Bemisia tabaci Gennadius when exposed to endophytically colonized B. bassiana and Metarhizium brunneum. Similar findings have already been reported by other researchers where no fungal outgrowth was discovered in cadavers of insects fed with endophytically colonized plants (ResquínRomero et al., 2016; Sánchez-Rodríguez et al., 2018). Many other studies showed no mycosis or only rare instances of mycosis from the cadavers (Cherry et al., 2004; QuesadaMoraga et al., 2009; Resquín-Romero et al., 2016; SánchezRodríguez et al., 2017). In our study we also did not observe fungal outgrowth in $H$. armigera colonized with $B$. bassiana; therefore, we hypothesize that toxins produced by $B$. bassiana are responsible for the mortality of test insect species. Beauveria bassiana produces beauvericins and bassianolide, beauveriolides, oosporein, tenellin, pyridovericin, pyridomacrolidin, bassiacridin and bassianin. By forming complexes with cations, beauvericin causes an increase in permeability of natural and artificial membranes. Beauvericin also induces programmed cell death similar to apoptosis (Waetjen et al., 2014). The toxin was cytotoxic (IC50 $0.5 \mu \mathrm{M}$ ) to a Spodoptera frugiperda (SF-9) cell line (Fornelli et al., 2004) and on the Colorado potato beetle ( $\mathrm{LC}_{50} 633 \mathrm{ppm}$ ) (Roberts et al., 1992). Feng et al. (2015) verified the role of oosporein in fungal virulence to host insects through the inhibition of insect defense mechanisms.

Bacillus thuringiensis toxins have also been found to be lethal to a vast array of insect pests belonging to the orders Coleoptera, Diptera, and Lepidoptera (Feitelson et al., 1992; Schnepf et al., 1998), and hence B. thuringiensis-spore crystal mixtures have been in used widely as bio-pesticides. For infection to occur $B$. thuringiensis toxins attach to the specific bindings sites of the insect's midgut which then leads to cell lysis. This lysis may result in the insect's cessation of feeding, lethargy and ultimately death (Marzban et al., 2009). The integrated use of entomopathogenic fungi and Bt has depicted effective control of insect pests (Mwamburi et al., 2009; Wakil et al., 2013), however, no comparable literature is available regarding the combination of endophytic fungi with $B$. thuringiensis against any insect species.

Integration of two or more entomopathogens to control insect pests may increase efficacy and the chances of targeting multiple hosts (Pingel and Lewis, 1999). Marzban et al. (2009) reported that the integration of two or more myco-pathogens interact positively relative to their individual effect. In many combinations, the virulence of an agent is enhanced by the action of the other agent, which resultantly increases the speed or magnitude of kill, and causes retarded growth and reduced feeding in the host. In combined treatments of $B$. thuringiensis and $B$. bassiana, both agents work synergistically weakening the insect and affecting the insect immune response to allow entomopathogens to infect the host more efficiently. When $B$. bassiana gains access to the insect gut, it boosts the infection of $B$. thuringiensis toxins. In this way both agents help each other in retardation of normal physiological functions of an insect host. These findings are further supported by Allee et al. (1990) who 
reported that $B$. bassiana germinating and invading the insect favors the activity of $B$. thuringiensis toxins to increase pathogenic severity in grubs of Colorado potato beetle.

The findings of our study revealed higher mortality levels of $H$. armigera larvae in combined treatments of $B$. bassiana inoculated chickpea leaves and $B$. thuringiensis compared to their sole applications. Synergistic interactions were recorded at intermediate doses of $B$. thuringiensis while, additive at low doses and antagonistic effects were observed at high dose rates. It would be interesting to explore why antagonism was observed at the highest dose that investigation is beyond the scope of this current study. Thus, as observed previously, interactions among entomopathogens can vary depending on the dosage of the microbial agents applied (Shapiro-Ilan et al., 2004). Synergistic interactions were reported by Wraight and Ramos (2005) when B. bassiana (GHA) and B. thuringiensis (Bt-k) were sprayed on potatoes to protect against $L$. decemlineata. Identical findings with dual applications of $B$. thuringiensis and $B$. bassiana were also reported in the same host by Furlong and Groden (2003). Other researchers observed similar results when combining $B$. thuringiensis and $B$. bassiana with synthetic insecticides (Fargues, 1975; Lewis and Bing, 1991). Contrarily, no synergism was observed between $B$. thuringiensis and $B$. bassiana against 4 th stage larvae of $L$. decemlineata (Costa et al., 2001). In such cases the method of fungal spore application may retard the synergistic effect and cause a differential response in terms of the level of mortality. Different responses of Chilo partellus were reported when fungal spores were applied on leaf disk compared to spray and dipping (Tefera and Pringle, 2003).

Developmental parameters of $H$. armigera were greatly affected by the treatments applied and were associated with rate of application. Similar to our findings, Khalique and Ahmad (2002) reported extended larval durations with increased Bt-k concentrations. The studies of Ma et al. (2008) and Marzban et al. (2009) also reported growth retardation of Ostrinia furnacalis and $H$. armigera when challenged with CrylAc from B. thuringiensistreated diets and combined action of B. thuringiensis (Cry1Ac) and $\mathrm{HaCPV}$, respectively. In the larval development assay, our findings indicated toxic effects of the pathogen as indicated by decreased frass production. These findings corroborate those of Marzban et al. (2009) who reported more food uptake in check treatments as compared to the treatments applied. Similarly, reduced frass production in Trichoplusia ni were reported with the increase of treatment concentrations (Janmaat et al., 2014). Surprisingly, we observed a peak in frass production in the

\section{REFERENCES}

Abbott, W. S. (1925). A method of computing the effectiveness of an insecticide. J. Econ. Entomol. 18, 265-267. doi: 10.1093/jee/18. $2.265 \mathrm{a}$

Ahmad, M., Arif, M. I., and Attique, N. R. (1997). Pyrethroid resistance Helicoverpa armigera (Lepidoptera: Noctuidae) in Pakistan. Bull. Entomol. Res. 87, 343-347. doi: $10.1017 /$ s0007485300037366

Akello, J., Dubois, T., Coyne, D., and Kyamanywa, S. (2008). Endophytic Beauveria bassiana in banana (Musa spp.) reduces banana weevil (Cosmopolites sordidus) combined treatment on day 11. It is not clear why this occurred yet it is known that food ingestion and thus frass production can be variable over an insect's life cycle (Moore et al., 1992; Hernández-Velázquez et al., 2002; Mohammadbeigi and Port, 2015). Nonetheless, overall we observed negative impacts of the treatments on larval fitness. These responses may be attributed to increased $B$. thuringiensis concentrations altering the protein to carbohydrate ratio of the diet, which resultantly disturbs the insect's growth response (Simpson and Raubenheimer, 1995). Reduced food consumption with $B$. thuringiensis treatments (Nathan et al., 2005; Ramalho et al., 2011), food utilization (Prutz and Dettner, 2005; Ramalho et al., 2011) and reduced larval weight has been reported previously.

This study provides evidence from the laboratory that combining $B$. bassiana and $B$. thuringiensis may provide high levels of synergistic control of $H$. armigera. A unique aspect of the study is that we utilized $B$. thuringiensis in combination with endophytic $B$. bassiana rather than aqueous fungal applications (as has been used in prior studies). Our laboratory findings of efficacy must be extended to field conditions in future research. Also, this novel approach of combining endophytic fungi with other microbial control applications should be investigated in other pest and cropping systems. This paper is fundamental and meant as proof of concept. As far as practical use, other methods for inoculating the plants with $B$. bassiana (such as foliar spray or seed dressing etc.) can be used on a larger scale.

\section{DATA AVAILABILITY STATEMENT}

All datasets generated for this study are included in the article/supplementary material.

\section{AUTHOR CONTRIBUTIONS}

WW conceived and designed research. MT and WW conducted experiments. MT, DS-I, and WW analyzed data and wrote the manuscript. WW, DS-I and AA-S edited and finalized the manuscript. All authors read and approved the manuscript.

\section{FUNDING}

This research work was financially supported (2AV1-257) by Higher Education Commission, Islamabad, Pakistan. fitness and damage. Crop. Prot. 27, 1437-1441. doi: 10.1016/j.cropro.2008. 07.003

Allee, L. L., Goettel, M. S., Golberg, A., Whitney, H. S., and Roberts, D. W. (1990). Infection by Beauveria bassiana of Leptinotarsa decemlineata larvae as a consequence of fecal contamination of the integument following per os inoculation. Mycopathologia 111, 17-24. doi: 10.1007/bf0227 7296

Arnold, A. E., and Herre, A. E. (2003). Canopy cover and leaf age affect colonization by tropical fungal endophytes: ecological pattern and process in Theobroma cacao (Malvaceae). Mycologia 95, 388-398. doi: 10.2307/3761880 
Arnold, A. E., and Lewis, L. C. (2005). "Ecology and evolution of fungal endophytes, and their roles against insects," in Insect-Fungal Associations: Ecology and Evolution, eds F. E. Vega and M. Blackwell (New York, NY: Oxford University Press), 74-96.

Arnold, A. E., Maynard, Z., Gilbert, G. S., Coley, P. D., and Kursar, T. A. (2000). Are tropical fungal endophytes hyperdiverse? Ecol. Lett. 3, 267-274. doi: 10. 1046/j.1461-0248.2000.00159.x

Arnold, A. E., Mejía, L. C., Kyllo, D., Rojas, E. I., Maynard, Z., Robbins, N., et al. (2003). Fungal endophytes limit pathogen damage in a tropical tree. Proc. Natl. Acad. Sci. U S A. 100, 15649-15654. doi: 10.1073/pnas.2533483100

Bamisile, B. S., Dash, C. K., Akutse, K. S., Qasim, M., Aguila, L. C. R., Wang, F., et al. (2019). Endophytic Beauveria bassiana in foliar-treated Citrus limon plants acting as a growth suppressor to three successive generations of Diaphorina citri Kuwayama (Hemiptera: Liviidae). Insects 10:176. doi: 10.3390/insects10060176

Barnett, H. L., and Hunter, B. B. (1999). Illustrated Genera of Imperfect Fungi, 4th Edn. St. Paul, MN: APS Press, The American Phytopathological Society.

Barta, M. (2018). In planta bioassay on the effects of endophytic Beauveria strains against larvae of horse-chestnut leaf miner (Cameraria ohridella). Biol. Control 121, 88-98. doi: 10.1016/j.biocontrol.2018.02.013

Bing, L. A., and Lewis, L. C. (1991). Suppression of Ostrinia nubilalis (Hübner) (Lepidoptera: Pyralidae) by endophytic Beauveria bassiana (Balsamo) Vuillemin. Environ. Entomol. 20, 1207-1211. doi: 10.1093/ee/20.4.1207

Bing, L. A., and Lewis, L. C. (1992a). Endophytic Beauveria bassiana (Balsamo) Vuillemin in corn: the influence of the plant growth stage and Ostrinia nubilalis (Hübner). Biocontrol Sci. Technol. 2, 39-47. doi: 10.1080/09583159209355216

Bing, L. A., and Lewis, L. C. (1992b). Temporal relationships between Zea mays, Ostrinia nubilalis (Lep.: Pyralidae) and endophytic Beauveria bassiana. Entomophaga 37, 525-536. doi: 10.1007/bf02372322

Biswas, C., DeyP, Satpathy, S., and Satya, P. (2012). Establishment of the fungal entomopathogen Beauveria bassiana as a season long endophyte in jute (Corchorus olitorius) and its rapid detection using SCAR marker. BioControl 57, 565-571. doi: 10.1007/s10526-011-9424-0

Cameron, P. J., Walker, G. P., and Herman, T. J. B. (1995). Development of resistance to fenvalerate in Helicoverpa armigera (Lepidoptera: Noctuidae) in New Zealand. NZ. J. Crop Hortic Sci. 23, 429-436. doi: 10.1080/01140671.1995. 9513920

Cannon, P. F., and Simmons, C. M. (2002). Diversity and host preference of leaf endophytic fungi in the Iwokrama Forest Reserve. Guyana. Mycologia 94, 210-220. doi: 10.2307/3761797

Chaudhary, J. P., and Chaudhary, S. D. (1975). Insect pests of gram and their control. Prog. Ping. HAU 1975, 52-59.

Cherry, A. J., Banito, A., Djegui, D., and Lomer, C. (2004). Suppression of the stem-borer Sesamia calamistis (Lepidoptera; Noctuidae) in maize following seed dressing, topical application and stem injection with African isolates of Beauveria bassiana. Int. J. Pest Manag. 50, 67-73.

Chhabra, K. (1980). "Pest problems in gram and their control," in Proceedings of, Discussion cum Training Seminar on Pest and Disease Management in Pulses, November, 11-18, (Ludhiana: PAU), 31-42.

Cornelissen, T. G., and Fernandes, G. W. (2001). Patterns of attack of two herbivore guilds in the tropical shrub Bauhinia brevipes (Leguminosae): vigor or chance? Eur. J. Entomol. 98, 37-40. doi: 10.14411/eje.2001.006

Costa, S. D., Barbercheck, M. E., and KennedyGG. (2001). Mortality of Colorado potato beetle (Leptinotarsa decemlineata) after sub-lethal stress with the CRYIIIA delta-endotoxin of Bacillus thuringiensis and subsequent exposure to Beauveria bassiana. J. Invertebr. Pathol. 77, 173-179. doi: 10.1006/jipa.2001. 5017

Crecchio, C., and Stotzky, G. (2001). Biodegradation and insecticidal activity of the toxin from Bacillus thuringiensis subsp. kurstaki bound on complexes of montmorillonite-humic acids-Al hydroxypolymers. Soil Biol. Biochem. 33, 573-581. doi: 10.1016/s0038-0717(00)00199-1

Damalas, C. A., and Koutroubas, S. D. (2018). Current status and recent developments in biopesticide use. Agriculture 8:13. doi: 10.3390/ agriculture 8010013

Evans, H. C., Holmes, K. A., and Thomas, S. E. (2003). Endophytes and mycoparasites associated with an indigenous forest tree, Theobroma gileri, in Ecuador and a preliminary assessment of their potential as biocontrol agents of cocoa diseases. Mycol. Prog. 2, 149-160. doi: 10.1007/s11557-006-0053-4
Fargues, T. (1975). Etude experimental dans la nature de Beauveria and Metarhizium a dose reduite contre Lephinotarsa decemlineata. Ann. Zool. Ecol. Anim. 7, 247-264.

Feitelson, J. S., Payne, J., and Kim, L. (1992). Bacillus thuringiensis: insects and beyond. Nat. Biotechnol. 10, 271-275. doi: 10.1038/nbt0392-271

Feng, P., Shang, Y., Cen, K., and Wang, C. (2015). Fungal biosynthesis of the bibenzoquinone oosporein to evade insect immunity. Proc. Natl. Acad. Sci. U.S.A. 112, 11365-11370. doi: 10.1073/pnas. 1503200112

Fernandes, G. W., Oki, Y., Sanchez-Azofeifa, A., Faccion, G., and AmaroArruda, H. C. (2011). Hail impact on leaves and endophytes of the endemic threatened Coccoloba cereifera (Polygonaceae). Plant Ecol. 212, 1687-1697. doi: 10.1007/ s11258-011-9941-z

Fornelli, F., Minervini, F., and Logrieco, A. (2004). Cytotoxicity of fungal metabolites to lepidopteran (Spodoptera frugiperda) cell line (SF-9). J. Invertebr. Pathol. 85, 74-79. doi: 10.1016/j.jip.2004.01.002

Furlong, M. J., and Groden, E. (2003). Starvation induced stress and the susceptibility of the Colorado potato beetle, Leptinotarsa decemlineata, to infection by Beauveria bassiana. J. Invertebr. Pathol. 83, 127-138. doi: 10.1016/ s0022-2011(03)00066- 1

Gómez-Vidal, S., Lopez-Llorca, L. V., Jansson, H. B., and Salinas, J. (2006). Endophytic colonization of date palm (Phoenix dactylifera L.) leaves by entomopathogenic fungi. Micron 37, 624-632. doi: 10.1016/j.micron.2006. 02.003

Gunning, R. V., Moores, G. D., and Devonshire, A. L. (1998). Insensitive acetycholinesterase causes resistance to organophosphates in Australia Helicoverpa armigera (Hübner) (Lepidoptera: Noctuidae). Pestic Sci. 54, 319-320. doi: 10.1002/(sici) 1096-9063(1998110)54:3<319::aid-ps839>3.0. co; $2-6$

Han, Z., Wang, Y., Zhang, Q., Li, X., and Li, G. (1999). Dynamics of pyrethroid resistance in the field population of Helicoverpa armigera (Hübner) in China. Pestic Sci. 55, 462-466. doi: 10.1002/(sici)1096-9063(199904)55:4<462::aidps931>3.0.co;2-c

Hernández, C. S., Andrew, R., Bel, Y., and Ferrée, J. (2005). Isolation and toxicity of Bacillus thuringiensis from potato-growing areas in Bolivia. J. Invertebr. Pathol. 88, 8-16. doi: 10.1016/j.jip.2004.10.006

Hernández-Velázquez, V. M., Berlanga-Padilla, A., and Toriello, C. (2002). Reduction of feeding by (Orthoptera: Acrididae), following infection by Schistocerca piceifrons piceifrons Metarhizium anisopliae var. Acridum. Florida Entomol. 90, 786-789. doi: 10.1653/0015-4040(2007)90[786:rofbsp]2.0.co;2

Hilarino, M. P. A., Silveira, F. A. O., Oki, Y., Rodrigues, L., Santos, J. C., Junior, A. C., et al. (2011). Distribution of the endophytic fungi community in leaves of Bauhinia brevipes (Fabaceae). Acta Botanica Brasilica 25, 815-821. doi: 10.1590/s0102-33062011000400008

Inglis, G. D., Gorttel, M. S., Butt, T. M., and Hermann, S. (2001). "Use of Hypomycetous fungi for the managing insect pests," in Fungi as Biocontrol agents: Progress, Problems and Potential. GBR, ed. T. M. Butt (Wallingford: CABI Publishing), 23. doi: 10.1079/9780851993560.0023

Jaber, L. R., Araj, S.-E., and Qasem, J. R. (2018). Compatibility of endophytic fungal entomopathogens with plant extracts for the management of sweetpotato whitefly Bemesia tabaci Gennadius (Homoptera: Aleyrodidae). Biol. Control 117, 164-171. doi: 10.1016/j.biocontrol.2017.11.009

Jalgaonwala, R. E., Mohite, B. V., and Mahajan, R. T. (2011). A review: natural products from plant associated endophytic fungi. J. Microbiol. Biotechnol. Res. $1,21-32$.

Janmaat, A. F., Bergmann, L., and Ericsson, J. (2014). Effect of low levels of Bacillus thuringiensis exposure on the growth, food consumption and digestion efficiencies of Trichoplusia ni resistant and susceptible to Bt. J. Invertebr. Pathol. 119, 32-39. doi: 10.1016/j.jip.2014.04.001

Jones, K. A. (1994). "Use of baculoviruses for cotton pest control," in Insect Pests of Cotton, eds G. A. Matthews and J. P. Tanstall (Walling ford: CAB International), 477-504.

Khalique, F., and Ahmad, K. (2002). Retarding effect of spore- $\delta$-endotoxin complex of Bacillus thuringiensis (Berliner) strains on the development of Helicoverpa armigera (Hubner). Pak. J. Biol. Sci. 5, 853-857. doi: 10.3923/pjbs.2002.853.857

Khan, M. A. (1979). "Chickpea report from Pakistan," in Proceedings of International Workshop on Chickpea Improvement, Hyderabad, India, February 28-March 02, 1979, (Patancheru: ICRISAT), 258-263. 
Kumar, S., and Singh, A. (2015). Biopesticides: present status and the future prospects. J. Fert Pestic 6, e129.

Leckie, B. M. (2002). Effects of Beauveria bassiana Mycelia and Metabolites Incorporated into Synthetic Diet and Fed to Larval Helicoverpa zea, and Detection of Endophytic Beauveria Bassiana in Tomato Plants Using PCR and ITS. Thesis, The University of Tennessee: Knoxville, TN, 75. Master's dissertation.

Lewis, L. C., and Bing, L. A. (1991). Bacillus thuringiensis Berliner and Beauveria bassiana (Balsamo) Vuillemin for European corn borer control: potential for immediate and season-long suppression. Can. Entomol. 123, 387-393. doi: 10.4039/ent123387-2

Lezama-Gutiérrez, R., Hamm, J. J., Molina-Ochoa, J., Lopez-Edwards, M., Pescador-Rubio, A., Gonzalez-Ramirez, M., et al. (2001). Occurrence of entomopathogens of Spodoptera frugiperda (Lepidoptera: Noctuidae) in the Mexican states of Michoacan, Colima, Jalisco and Tamaulipas. Fla Entomol. 84, 23-30.

Ma, X. M., LiuXX, NingX, Zhang, B., Han, F., Guan, X.-M., et al. (2008). Effects of Bacillus thuringiensis toxin CrylAc and Beauveria bassiana on Asiatic corn borer (Lepidoptera: Crambidae). J. Invertebr. Pathol. 99, 123-128. doi: 10.1016/ j.jip.2008.06.014

Mansour, N. A., Eldefrawi, M. E., Toppozada, A., and Zeid, M. (1966). Toxicological studies on the Egyptian cotton leafworm, Prodenia litura Vl potentiation and antagonism of carbamate insecticide. J. Econ. Entomol. 59, 307-311. doi: 10.1093/jee/59.2.307

Marrone, P. G. (2014). "The market and potential for biopesticides," in Biopesticides: State of the Art and Future Opportunities, eds A. D. Gross, J. R. Coats, S. O. Duke, and J. N. Seiber (Washington DC: American Chemical Society Symposium Series), 245-258. doi: 10.1021/bk-2014-1172.ch016

Martin, T., Ochou, G. O., Hala-N'Klo, F., Wassal, J., and Waissayre, M. (2000). Pyrethroid resistance in cotton bollworm Helicoverpa armigera in West Africa. Pest. Manag. Sci. 56, 549-554.

Marzban, R., He, Q., Liu, X., and Zhang, Q. (2009). Effects of Bacillus thuringiensis toxin CrylAc and cytoplasmic polyhedrosis virus of Helicoverpa armigera (Hübner) (HaCPV) on cotton bollworm (Lepidoptera: Noctuidae). J. Invertebr. Pathol. 101, 71-76. doi: 10.1016/j.jip.2009.02.008

Mohammadbeigi, A., and Port, G. (2015). Effect of infection by Beauveria bassiana and Metarhizium anisopliae on the feeding of Uvarovistia zebra. J. Insect. Sci. 15:88. doi: 10.1093/jisesa/iev033

Moore, D., Reed, M., Le Patourel, G., Abraham, Y. J., and Prior, C. (1992). Reduction of feeding by the desert locust, Schistocerca gregaria, after infection with Metarhizium flavoviride. J. Invertebr. Pathol. 60, 304-307. doi: 10.1016/ 0022-2011(92)90013-t

Mwamburi, L. A., Laing, M. D., and Miller, R. (2009). Interaction between Beauveria bassiana and Bacillus thuringiensis var. israelensis for the control of house fly larvae and adults in poultry houses. Poultry Sci. 88, 2307-2314. doi: 10.3382/ps.2009-00212

Nathan, S. S., Chung, P. G., and Murugan, K. (2005). Effect of biopesticides applied separately or together on nutritional indices of the rice leaf folder, Cnaphalocrocis medinalis. Phytoparasitica 33, 187-195. doi: 10.1007/ bf03029978

Nguyen, T. H. N., Borgemeister, C., Poehling, H., and Zimmermann, G. (2007). Laboratory investigations on the potential of entomopathogenic fungi for biocontrol of Helicoverpa armigera (Lepidoptera: Noctuidae) larvae and pupae. Biocontrol. Sci. Tech. 17, 853-864. doi: 10.1080/0958315070154 6375

O’Hanlon, K. A., Knorr, K., Jørgensen, L. N., Nicolaisen, M., and Boelt, B. (2012). Exploring the potential of symbiotic fungal endophytes in cereal disease suppression. Biol. Control 63, 69-78. doi: 10.1016/j.biocontrol.2012.08.007

Olson, S. (2015). An analysis of the biopesticide market now and where is going. Outlooks Pest Manag. 26, 203-206. doi: 10.1564/v26_oct_04

Parsa, S., Ortiz, V., and Vega, F. E. (2013). Establishing fungal entomopathogens as endophytes: towards endophytic biological control. J. Vis. Exp. 74:50360.

Pingel, R. L., and Lewis, L. C. (1999). Effect of Bacillus thuringiensis, Anagrapha falcifera multiple nucleopolyhedro virus, and their mixture on three Lepidoptera corn ear pests. J. Econ. Entomol. 92, 91-96. doi: 10.1093/jee/92.1.91

Posada, F., Aime, M. C., Peterson, S. W., Rehner, S. A., and Vega, F. E. (2007). Inoculation of coffee plants with the fungal entomopathogen Beauveria bassiana (Ascomycota: Hypocreales). Mycol. Res. 111, 749-758.
Posada, F. J., and Vega, F. E. (2005). Establishment of the fungal entomopathogen Beauveria bassiana (Ascomycota: Hypocreales) as an endophyte in cocoa seedlings (Theobroma cacao). Mycologia 97, 1195-1200. doi: 10.3852/ mycologia.97.6.1195

Powell, W. A., Klingeman, W. E., Ownley, B. H., and Gwinn, K. D. (2009). Evidence of endophytic Beauveria bassiana in seed-treated tomato plants acting as a systemic entomopathogen to larval Helicoverpa zea (Lepidoptera: Noctuidae). J. Entomol. Sci. 44, 391-396. doi: 10.18474/0749-8004-44.4.391

Powell, W. A., Klingeman, W. E., Ownley, B. H., Gwinn, K. D., Dee, M., and Flanagan, P. C. (2007). "Endophytic Beauveria bassiana in tomatoes yields mycosis in tomato fruit worm larvae," in Proceedings of the 104th Annual Meeting American Society for Horticultural Science, Scottsdale, July16-19, 2007, (Arizona, Ariz).

Prutz, G., and Dettner, K. (2005). Effects of various concentrations of Bacillus thuringiensis Corn leaf material on food utilization by Chilo partellus larvae of different ages. Phytoparasitica 33, 467-479. doi: 10.1007/bf02981396

Qayyum, M. A., Wakil, W., Arif, M. J., Sahi, S. T., and Dunlap, C. A. (2015). Infection of Helicoverpa armigera by endophytic Beauveria bassiana colonizing tomato plants. Biol. Control 90, 200-207. doi: 10.1016/j.biocontrol.2015.04.005

Quesada-Moraga, E., López-Díaz, C., and Landa, B. B. (2014). The hidden habit of the entomopathogenic fungus Beauveria bassiana: first demonstration of vertical plant transmission. PLoS One 9:e89278. doi: 10.1371/journal.pone. 0089278

Quesada-Moraga, E., Muñoz-Ledesma, F., and Santiago-Alvarez, C. (2009). Systemic protection of Papaver somniferum L. against Iraella luteipes (Hymenoptera: Cynipidae) by an endophytic strain of Beauveria bassiana (Ascomycota: Hypocreales). Environ. Entomol. 38, 723-730. doi: 10.1603/022. 038.0324

Ramakuwela, T., Hatting, J., Bock, C., Vega, F. E., Wells, L., Mbata, G. N., et al. (2019). ). Establishment of Beauveria bassiana as a fungal endophyte in pecan (Carya illinoinensis) seedlings and its virulence against pecan insect pests. Biol. Control 140:104102. doi: 10.1016/j.biocontrol.2019.104102

Ramalho, F. D., Azeredo, T. L., de Nascimento, A. R. B., Fernandes, F. S., Nascimento, JL. Jr., et al. (2011). Feeding of fall armyworm, Spodoptera frugiperda, on Bt transgenic cotton and its isoline. Entomol. Exp. Appl. 139, 207-214. doi: 10.1111/j.1570-7458.2011.01121.x

Rao, G. V., Visalakshrmi, V., Suganthy, M., Reddy, P. V., Reddy, Y. V. R., and Rao, V. R. (2008). Relative toxicity of neem to natural enemies associated with the chickpea ecosystem: a case study. Int. J. Trop. Insect. Sci. 27, 229-235. doi: 10.1017/s1742758407877459

Resquín-Romero, G., Garrido-Jurado, I., Delso, C., Ríos-Moreno, A., and QuesadaMoraga, E. (2016). Transient endophytic colonizations of plants improve the outcome of foliar applications of mycoinsecticides against chewing insects. J. Invertebr. Pathol. 136, 23-31. doi: 10.1016/j.jip.2016.03.003

Roberts, D. W., Gupta, S., Leger, and RJSt. (1992). Metabolite production by entomopathogenic fungi. Pesq Agropec Bras 27, 325-347.

Rodriguez, R. J., White, JF. Jr., Arnold, A. E., and Redman, R. S. (2009). Fungal endophytes: diversity and functional roles. New Phytol. 182, 314-330. doi: 10.1111/j.1469-8137.2009.02773.x

Roy, H. E., Steinkraus, D. C., Eilenberg, J., Hajek, A. E., and Pell, J. K. (2006). Bizarre interactions and endgames: entomopathogenic fungi and their arthropod hosts. Ann. Rev. Entomol. 51, 331-357. doi: 10.1146/annurev.ento.51.110104.150941

Salama, H. S., Foda, M. S., El-Bendary, M. A., and Abdel-Razek, A. (2004). Infection of red palm weevil Rhynchophorus ferrugineus, by spore-forming bacilli indigenous to its natural habitat in Egypt. J. Pest Sci. 77, 27-31. doi: 10.1007/s10340-003-0023-4

Sánchez-Rodríguez, A. R., Raya-Díaz, S., Zamarreño, A. M., García-Mina, J. M., del Campillo, M. C., and Quesada-Moraga, E. (2017). An endophytic Beauveria bassiana strain increases spike production in bread and durum wheat plants and effectively controls cotton leafworm (Spodoptera littoralis) larvae. Biol. Control $116,90-102$.

Sánchez-Rodríguez, A. R., Raya-Díaz, S., Zamarreño, Ám, García-Mina, J. M., del Campillo, M. C., et al. (2018). An endophytic Beauveria bassiana strain increases spike production in bread and durum wheat plants and effectively controls cotton leafworm (Spodoptera littoralis) larvae. Biol. Control 116, 90-102. doi: 10.1016/j.biocontrol.2017.01.012

Sandhu, S. S., Rajak, R. C., and Agarwal, G. P. (1993). Studies on prolonged storage of Beauveria bassiana conidia: effects of temperature and relative humidity on 
conidial viability and virulence against chickpea borer, Helicoverpa armigera. Biocontrol Sci. Technol. 3, 47-53. doi: 10.1080/09583159309355258

Sandner, H., and Cichy, D. (1967). Research on the effectiveness of fungal and bacterial insecticides. Ekol Pol Ser A 15, 325-333.

Schnepf, E., Crickmore, N., Van Rie, J., Lereclus, D., Baum, J., Feitelson, J., et al. (1998). Bacillus thuringiensis and its pesticidal crystal proteins. Microbiol. Mol. Biol. Rev. 62, 775-806. doi: 10.1128/mmbr.62.3.775-806.1998

Schulz, B., and Boyle, C. (2005). The endophytic continuum. Mycol. Res. 109, 661-686. doi: 10.1017/s095375620500273x

Shapiro-Ilan, D. I., Jackson, M., Reilly, C. C., and Hotchkiss, M. W. (2004). Effects of combining an entomopathogenic fungi or bacterium with entomopathogenic nematodes on mortality of Curculio caryae (Coleoptera: Curculionidae). Biol. Control 30, 119-126. doi: 10.1016/j.biocontrol.2003.09.014

Sharma, H. C., Gowda, C. L. L., Stevenson, P. C., Ridsdill-Smith, T. J., Clement, S. L., Rao, G. V. R., et al. (2007). "Host plant resistance and insect pest management in chickpea," in Chickpea Breeding and Management, eds S. S. Yadav, R. R. Redden, W. Chen, and B. Sharma (Wallingford: CAB International), 520-537. doi: 10.1079/9781845932138.025

Simpson, S. J., and Raubenheimer, D. (1995). The geometric analysis of feeding and nutrition: a user's guide. J. Insect Physiol. 41, 545-553. doi: 10.1016/00221910(95)00006-g

Sokal, R., and Rohlf, F. J. (1995). Biometry, 3rd Edn. New York, NY: Freeman \& Co.

Suryanarayanan, T. S., and Thennarasan, S. (2004). Temporal variation in endophyte assemblages of Plumeria rubra leaves. Fungal Divers 15, 97-204.

Tay, W. T., Soria, M. F., Walsh, T., Thomazoni, D., Silvie, P., Behere, G. T., et al. (2013). A brave new world for an old world pest: Helicoverpa armigera (Lepidoptera: Noctuidae) in Brazil. PLoS One 8:e80134. doi: 10.1371/journal. pone. 0080134

Tefera, T., and Pringle, K. L. (2003). Effect of exposure method to Beauveria bassiana and conidia concentration on mortality, mycosis, and sporulation in cadavers of Chilo partellus (Lepidoptera: Pyralidae). J. Invertebr. Pathol. 80, 90-95. doi: 10.1016/j.jip.2003.08.001

Tefera, T., and Vidal, S. (2009). Effect of inoculation method and plant growth medium on endophytic colonization of sorghum by the entomopathogenic fungus Beauveria bassiana. BioControl 54, 663-669. doi: 10.1007/s10526-0099216-y

Tejesvi, M. V., Kini, K. R., Prakash, H. S., Subbiah, V., and Shetty, H. S. (2007). Genetic diversity and antifungal activity of species of Pestalotiopsis isolated as endophytes from medicinal plants. Fungal Divers 24, 37-54.

Vega, F. E. (2008). Insect pathology and fungal endophytes. J. Invertebr. Pathol. 98 , 277-279. doi: 10.1016/j.jip.2008.01.008

Vega, F. E., Posada, F., Aime, M. C., Pava-Ripoll, M., Infante, F., and Rehner, S. A. (2008). Entomopathogenic fungal endophytes. Biol. Control 46, 72-82. doi: 10.1016/j.biocontrol.2008.01.008

Waetjen, W., Debbab, A., Hohlfeld, A., Chovolou, Y., and Proksch, P. (2014). The mycotoxin beauvericin induces apoptotic cell death in H4IIE hepatoma cells accompanied by an inhibition of NF-KB-activity and modulation of MAPkinases. Toxicol. Lett. 231, 9-16. doi: 10.1016/j.toxlet.2014.08.021
Wagner, B. L., and Lewis, L. C. (2000). Colonization of corn, Zea mays, by the entomopathogenic fungus Beauveria bassiana. Appl. Environ. Microbiol. 66, 3468-3473. doi: 10.1128/aem.66.8.3468-3473.2000

Wakil, W., Ghazanfar, G. U., Riasat, T., Qayyum, M. A., Ahmed, S., and Yasin, M. (2013). Effects of interactions among Metarhizium anisopliae, Bacillus thuringiensis and chlorantraniliprole on the mortality and pupation of six geographically distinct Helicoverpa armigera field populations. Phytoparasitica 41, 221-234. doi: 10.1007/s12600-012-0282-9

Wakil, W., Ghazanfar, M. U., Nasir, F., Qayyum, M. A., and Tahir, M. (2012). Insecticidal efficacy of Azadirachta indica, nucleopolyhedrovirus and chlorantraniliprole singly or combined against field populations of Helicoverpa armigera Hübner (Lepidoptera: Noctuidae). Chilean J. Agric Res. 72, 53-61. doi: $10.4067 /$ s0718-58392012000100009

Wakil, W., Ghazanfar, M. U., Sahi, S. T., Kwon, Y. J., and Qayyum, M. A. (2011). Effect of modified meridic diet on the development and growth of tomato fruit worm Helicoverpa armigera (Lepidoptera: Noctuidae). Entomol. Res. 41, 88-94. doi: 10.1111/j.1748-5967.2011.00323.x

Watson, D. W., Geden, C. J., Long, S. J., and Rutz, D. A. (1995). Efficacy of Beauveria bassiana for controlling the house fly and stable fly (Diptera: Muscidae). Biol. Control 5, 405-411. doi: 10.1006/bcon.1995.1048

Waweru, B., Turoop, L., Kahangi, E., Coyne, D., and Dubois, T. (2014), Non-pathogenic Fusarium oxysporum endophytes provide field control of nematodes, improving yield of banana (Musa sp.). Biol. Control 74, 82-88. doi: 10.1016/j.biocontrol.2014.04.002

White, J. F., Bacon, C. W., Hywel-Jones, N. L., and Spatafora, J. W. (2003). Clavicipitalean Fungi: Evolutionary Biology, Chemistry, Biocontrol and Cultural Impacts. New York, NY: Marcel Dekker.

Wraight, S. P., and Ramos, M. E. (2005). Synergistic interaction between Beauveria bassiana and Bacillus thuringiensis tenebrionis-based biopesticides applied against field populations of Colorado potato beetle larvae. J. Invertebr. Pathol. 90, 139-150. doi: 10.1016/j.jip.2005.09.005

Wraight, S. P., and Ramos, M. E. (2017). Characterization of the synergistic interaction between Beauveria bassiana strain GHA and Bacillus thuringiensis morrisoni strain tenebrionis applied against Colorado potato beetle larvae. J. Invertebr. Pathol. 144, 47-57. doi: 10.1016/j.jip.2017.01.007

Yang, Y., Li, Y., and Wu, Y. (2013). Current status of insecticide resistance in Helicoverpa armigera after 15 years of Bt cotton planting in China. J. Econ. Entomol. 106, 375-381. doi: 10.1603/ec12286

Conflict of Interest: The authors declare that the research was conducted in the absence of any commercial or financial relationships that could be construed as a potential conflict of interest.

Copyright $\odot 2020$ Wakil, Tahir, Al-Sadi and Shapiro-Ilan. This is an open-access article distributed under the terms of the Creative Commons Attribution License (CC BY). The use, distribution or reproduction in other forums is permitted, provided the original author(s) and the copyright owner(s) are credited and that the original publication in this journal is cited, in accordance with accepted academic practice. No use, distribution or reproduction is permitted which does not comply with these terms. 